\title{
Pemanfaatan Media Pembelajaran Geografi Berbantuan Quizizz sebagai Strategi Pembelajaran Masa Pendemi Covid-19 pada Peserta Didik Kelas XII IPS 5 Semester 2 SMA Negeri 3 Purwokerto Tahun Pelajaran 2020/2021
}

\author{
The Utilization of Learning Media of Geography Using Quizizz as A Leaning Strategy during \\ the Covid-19 Pandemic towards Students on Class of XII Social Sciences Major 5 of the \\ Second Semester SMA Negeri 3 Purwokerto \\ School Year of 2020/2021
}

Wahyuliani

SMA Negeri 3 Purwokerto

\begin{abstract}
ARTICLE INFO
Article history:

DOI:

10.30595/pssh.v1i.80

Submitted:

April 12, 2021

Accepted:

June 10, 2021

Published:

June 14, 2021

Keywords:

Learning media, Quizizz, Covid-19

ABSTRACT

In line with the expectations of the government, parents and the public on the quality of Indonesian education both academic and non-academic, namely the character of students, it is necessary to creativity and innovation of teachers in teaching and learning activities in the midst of the Covid-19 pandemic. Geography subjects are subjects of interest that are mandatory and important for ips majors, so it should be students majoring in IPS master the lessons that are characteristic of the department, while some students say the geography of boring material let alone learning in the era of Covid-19 protesters where teachers do not come face to face with students. These things that cause low learning outcomes because boredom has an impact on the lack of interest and yearly curiosity in the material delivered by the teacher. The teacher's strategy in addressing the problem is to make use of quizizz-assisted geography learning media. The purpose of writing this paper is to describe the use of geography learning media assisted by quizizz as a learning strategy for the Covid-19 protesters in students of Class XII IPS 5 Semester 2 SMA N 3 Purwokerto Year 2020/2021. The use of geography-assisted learning media quizizz can improve the learning outcomes and the spirit of student competition on remote sensing materials. Evalution results after learning is the percentage of completion of learners $89.7 \%$ and has exceeded $75 \%$ of the number of learners so that the learning is declared effective.
\end{abstract}

This work is licensed under a Creative Commons Attribution 4.0 International License.

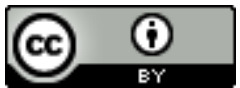

Corresponding Author:

Wahyuliani

Guru Geografi SMA Negeri 3 Purwokerto,

Jalan Kamandaka Barat No.3 Purwokerto, Jawa Tengah, Indonesia

Email: wahyuliani1976@gmail.com

\section{PENDAHULUAN}

Pembelajaran jarak jauh di tengah pendemi Covid-19 menjadi tantangan guru, peserta didik, orangtua dan pemerintah. Dampak Covid-19 terhadap implementasi pembelajaran daring dapat terlaksana dengan cukup baik apabila adanya kerjasama antara guru, siswa dan orang tua dalam belajar di rumah[1]. Media pembelajaran merupakan salah satu faktor yang sangat mempengaruhi hasil belajar peserta didik. Guru dituntut mampu memilih media pembelajaran yang dapat mengembangkan kemampuan peserta didik baik kemampuan kognitif, afektif maupun psikomotorik[2]. Pembelajaran Geografi di SMA Negeri 3 Purwokerto mendorong guru untuk mampu memilih 
alternatif solusi agar pembelajaran jarak jauh dapat berjalan dengan efektif. Mata pelajaran geografi adalah mata pelajaran peminatan yang wajib dan penting bagi peserta didik jurusan IPS, maka sudah seharusnya peserta didik jurusan IPS menguasai materi pelajaran geografi yang menjadi ciri khas jurusan selain ekonomi dan sosiologi. Mata pelajaran geografi untuk kelas XII sesuai struktur program kurikulum diberikan 4 jam per minggu dalam 2 kali tatap muka per minggu. Salah satu media yang bisa digunakan guru dalam pembelajaran ditengah pandemi Covid-19 pada mata pelajaran geografi yaitu media berbasis game interaktif dengan aplikasi quizizz[3].

Quizizz merupakan sebuah web tool untuk membuat permainan kuis interaktif untuk digunakan dalam pembelajaran. Media pembelajaran adalah alat yang membantu proses belajar mengajar dan berfungsi untuk memperjelas makna pesan yang disampaikan guna mencapai tujuan pembelajaran yang telah ditetapkan. Seiring perkembangan zaman, media pembelajaran juga tergolong dalam bentuk non-fisik (software)[4]. Quizizz merupakan salah satu media pembelajaran berbasis digital dan online (dapat digunakan jika ada dukungan internet yang memadai) yang terdiri dari fitur kuis, survey, game, kuis, maupun diskusi. Aplikasi Quizizz sendiri dideskripsikan sebagai sebuah web tool untuk membuat permainan kuis interaktif yang dapat dijalankan menggunakan gawai dan dapat diakses melalui website www.Quizizz.com[5]. Aplikasi Quizizz memungkinkan pendidik untuk membuat suatu penilaian formatif yang dikemas secara menarik bagi peserta didik. Dalam aplikasi ini juga menampilkan hasil dari setiap soal yang sudah dikerjakan oleh peserta didik melalui tampilan peringkat berdasarkan jumlah jawaban yang benar selain itu melalui aplikasi ini pendidik dimudahkan karena jawaban dari peserta didik dapat diketahui dan diunduh dengan format excel.

Hasil dari penelitian Yoselia Alvi Kusuma mengatakan bahwa hasil ulangan yang dilakukan oleh peserta didik menghasilkan persentase ketuntasan sebesar $91,30 \%$ dan sudah melebihi $75 \%$ dari jumlah peserta didik sehingga sudah dinyatakan efektif [6]. Yulia Isratul Aini menuliskan bahwa quizizz dapat menghasilkan media pembelajaran yang kreatif, inovatif dan menyenangkan sehingga perlu dimanfaatkan sebagai media pembelajaran [3]. Beberapa kajian terkait dengan media quizizz menunjukkan bahwa manfaat quizizz sangat membantu peseta didik dalam meningkatkan motivasi dan jiwa bersaing peserta didik dan mendorong untuk dapat memahami materi pembelajaran yang diberikan guru. Pemanfaatan media pembelajaran quizizz merupakan salah satu upaya mengakomodir permasalahan media pembelajaran yang masih konvensional. Pembelajaran berbasis TIK dalam pembelajaran daring dapat peningkatan kompetensi dan motivasi belajar peserta didik karena media pembelajaran yang dihasilkan memberikan model pembelajaran yang inovatif, kreatif dan menyenangkan[7]. Pembelajaran di masa pandemi Covid19 yang diharapkan bagi generasi $\mathrm{Z}$ yaitu bagaimana guru berperan dalam pembelajaran yang memungkinkan untuk peserta didik terjadi pembelajaran yang efektif atau bisa mencapai hasil sesuai tujuan[8]. Kebutuhan pembelajaran daring menjadi keharusan yang perlu disikapi guru agar dapat menjalankan tugas pokok dan fungsinya[9]. Berdasarkan paparan tersebut maka permasalahannya adalah bagaimanakah pemanfaatan media pembelajaran geografi berbantuan quizizz sebagai strategi pembelajaran masa pandemi Covid-19?

\section{METODE PENELITIAN}

Metode yang digunakan dalam penelitian ini merupakan penelitian deskriptif yang bertujuan untuk mendeskripsikan strategi pemanfaatan media pembelajaran geografi berbantuan quizizz untuk meningkatkan hasil belajar dan jiwa kompetisi peserta didik. Berbantuan quizizz yang dimaksud dalam penelitian ini adalah pembelajaran yang diahiri dengan game interaktif untuk evaluasi dengan menggunakan media pembelajaran yang dapat diakeses menggunakan layanan internet. Cara yang digunakan untuk menjawab permasalahan adalah dengan melakukan evaluasi bentuk tes di akhir pembelajaran dan melakukan observasi dalam pengumpulan data selama proses pembelajaran jarak jauh dengan menggunkan quizizz sebagai media pembelajaran di google classroom. Rubrik yang menjadi standar penilaian adalah : Amat Baik (86 - 100), Baik (71-85), Cukup (56-70) dan Kurang (<56). Dalam penelitian ini objek yang diamati adalah kegiatan peserta didik yang terkait dengan respon materi yang disampaikan dalam forum pembelajaran jarak jauh. Kegiatan pembelajaran dilaksanakan pada bulan Januari sampai dengan Februari semester 2 Tahun Pelajaran 2020/2021 pada kelas XII IPS 5 SMA Negeri 3 Purwokerto Melalui LMS Googleclassroom. Analisis data penelitian dilakukan menggunakan model analisis deskriptif kuantitatif dengan perhitungan rata-rata nilai peserta didik dan prosentase untuk melihat ketuntasan belajar dan analisis kualitatif untuk menjelaskan pemanfaatan media quizizz dalam pembelajaran geografi.

\section{HASIL PENELITIAN}

Pemanfaatan media pembelajaran geografi berbantuan quizizz sebagai strategi pembelajaran masa pandemi Covid-19 di kelas XII IPS 5 pada mata pelajaran geogafi dilaksanakan secara daring karena kebijakan pembelajaran jarak jauh dari bulan Maret 2020 sampai Maret 2021 masih berlaku di Kabupaten Banyumas. Pemanfaatan quizizz sebagai media pembelajaran dilaksanakan dengan LMS google classroom yang telah dimanfaatkan guru dan peserta didik selama pembelajaran jarak jauh. Google classroom memudahkan guru dalam mengelola kelas baik dalam kegiatan penyampaian materi, diskusi, maupun penilaian hasil kerja peserta didik dan evaluasi. Evaluasi dengan quizizz mempermudah guru dalam menyusun soal yaitu dengan klik Membuka Link http://quizizz.com/admin/ dan guru melihat langsung hasil nilai peserta didik yang dapat di download dalam bentuk exel. Siswa untuk bisa bergabung 
dengan quizizz dengan Masuk ke alamat www.quizizz.com/join/. Berikut contoh gambar dalam pembelajaran geografi berbantuan quizizz dengan LMS google classroom:

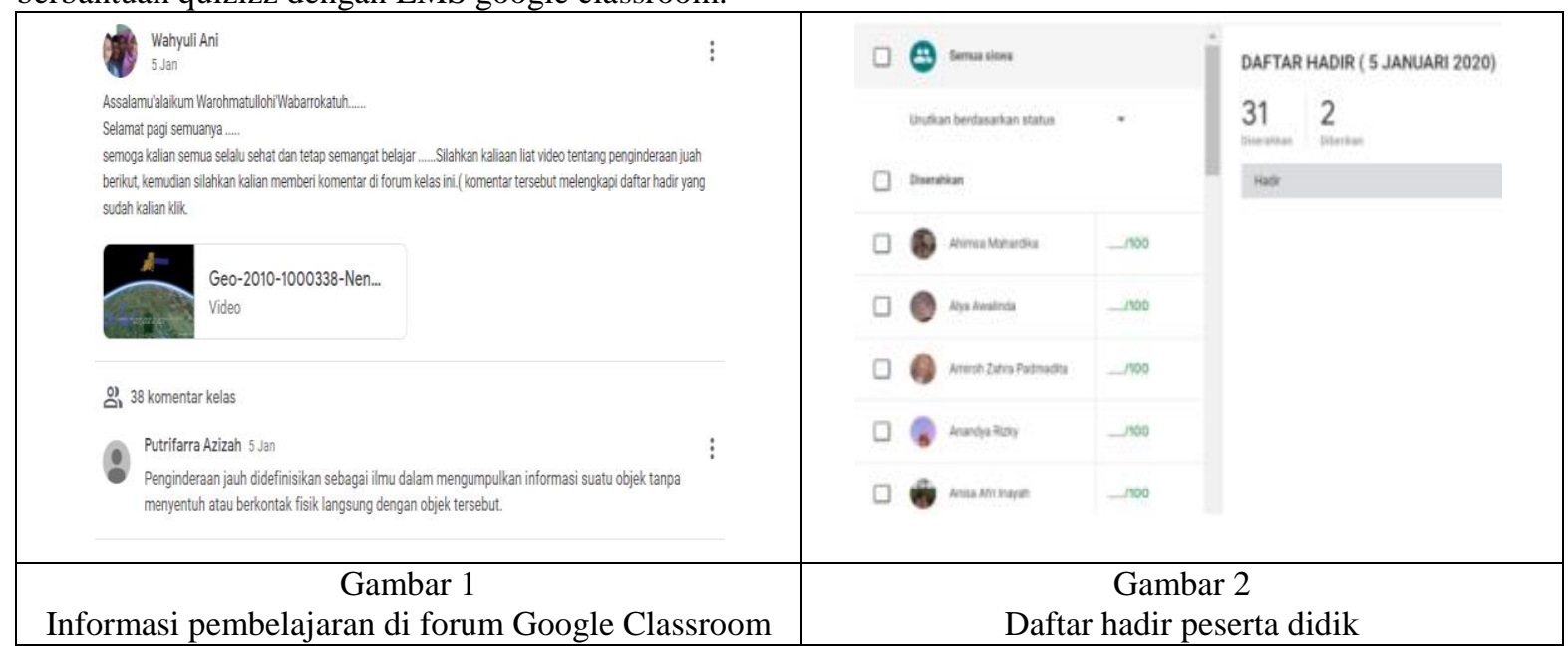

Proses pembelajaran dengan evalusi berbantuan quizizz berlangsung aktif. peserta didik menjadi lebih termotivasi untuk belajar karena pada pertemuan sebelumnya, guru telah terlebih dahulu meberikan materi dalam bentuk video sehingga peserta didik dapat mepersiapakan baik dalam pembelajaran maupun evalusi yang akan dilakukan. Berikut contoh gambar dalam pembelajaran geogafi dengan google meet dengan materi berbentuk video:

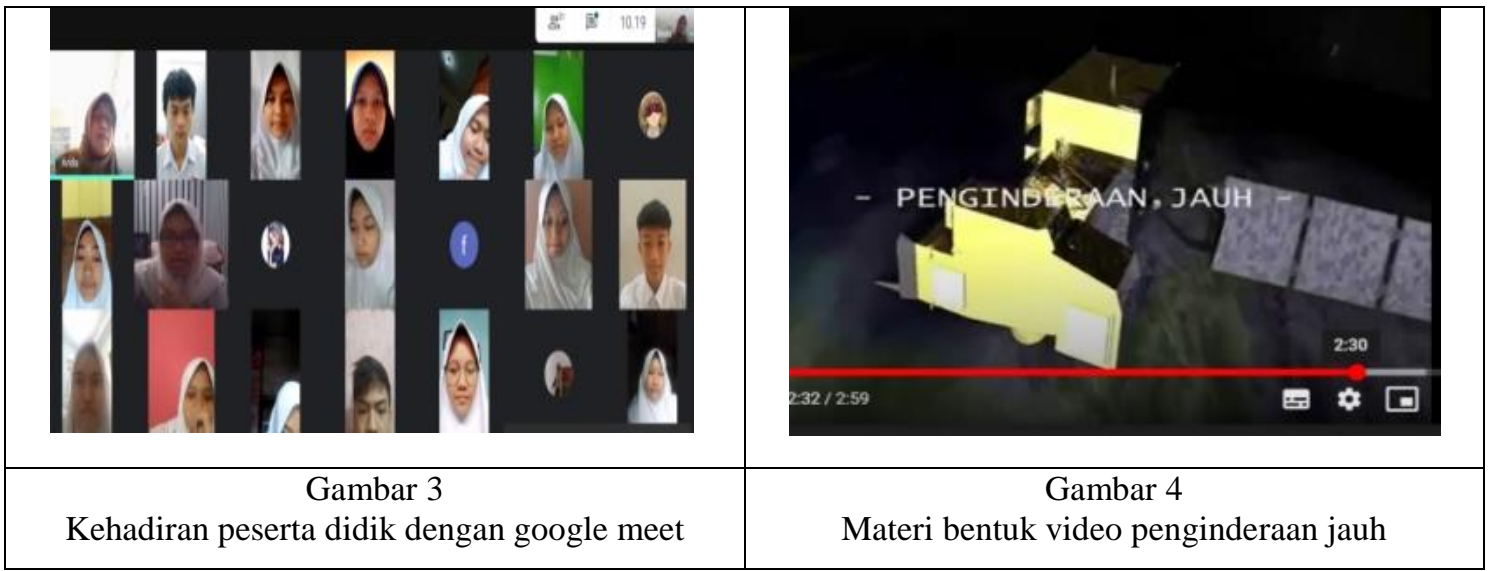

Pembelajaran dengan evalusi berbantuan quizizz mendorong peserta didik untuk belajar dalam suasana senang karena evalusi ini berbentuk game yang dilengkapi berbagai fitur dan tampilan yang menarik serta dapat langsung melihat hasil peserta didik. Berikut gambar dalam pembelajaran geografi berbantuan quizizz:

\begin{tabular}{|c|c|c|c|c|c|c|c|c|}
\hline 1 & \multicolumn{3}{|c|}{ Quizizz: Sistem Penginderaan Jauh } & & \multicolumn{4}{|c|}{ Quizizz: Sistem Penginderaan Jauh } \\
\hline${ }_{3}^{2}$ & \multicolumn{3}{|c|}{ Quiz started on: Tue 09, Feb 07:17 AM Total Attendance: 31 Average Sco } & & \multirow{2}{*}{\multicolumn{4}{|c|}{ Quiz started on: Tue 09, Feb 07:17 AM Total Attendance: 31 Average S }} \\
\hline 4 & \multirow{3}{*}{ Questions } & & $\mathrm{Cla}$ & 3 & & & & \\
\hline & & \multirow{2}{*}{ \# Correct } & \multirow{2}{*}{$\# 1$} & 4 & Players & Score & Accuracy & Started At \\
\hline t & & & & 5 & $\begin{array}{l}\text { Rahmat Slamet } \\
\text { Effendi (Rahmat }\end{array}$ & 15780 & $100 \%$ & Tue 09, Feb 03:31 AM \\
\hline $\begin{array}{l}7 \\
8\end{array}$ & Alat yang digunakan untuk mengindra disebut ... & 28 & & 6 & $\begin{array}{l}\text { Devina nur zalfa } \\
\text { soraya ( Devina nur. }\end{array}$ & 12850 & $100 \%$ & Tue 09, Feb 03:01 AM \\
\hline 9 & $\begin{array}{l}\text { Tenaga yang bersifat sinar buatan jika dilakukan pemotretan } \\
\text { pada malam hari dinamakan ... }\end{array}$ & 25 & & 7 & $\begin{array}{l}\text { Eka Rachmalia (Eka } \\
\text { Rachmalia) }\end{array}$ & 12660 & $100 \%$ & Tue 09, Feb 02:47 AM \\
\hline 10 & Manfaat dari citra pengindraan jauh dibidang hidrologi adalah & 23 & & 8 & $\begin{array}{l}\text { Amiroh Zahra } \\
\text { Padmadita (Amiroh }\end{array}$ & 11960 & $100 \%$ & Tue 09, Feb 02:42 AM \\
\hline 11 & $\begin{array}{l}\text { Kendaraan/media yang digunakan untuk membawa sensor guna } \\
\text { memperoleh gambaran objek adalah .... }\end{array}$ & 24 & & 9 & $\begin{array}{l}\text { Rafly Mukti Dewanto } \\
\text { (Rafly Dewanto) }\end{array}$ & 11760 & $100 \%$ & Tue 09, Feb 03:16 AM \\
\hline & $\begin{array}{c}\text { Gambar } 5 \\
\text { Hasil jawaban peserta didik }\end{array}$ & iap soa & & & & $\begin{array}{r}\mathrm{C} \\
\text { eval }\end{array}$ & ar 6 & $\operatorname{dik}$ \\
\hline
\end{tabular}


Pembelajaran dengan evalusi berbantuan quizizz pertemuan sebelumya peserta didik telah melakukan kegiatan mengamati tayangan vidio tentang penginderaan jauh, peserta didik dapat menyimpulkan konsep-konsep dasar penginderaan jauh yang harus dipahami. Penerapan pembelajaran berbantuan video meningkatkan kemampuan peserta didik untuk berpikir kritis (Critical Thinking). Hal ini dapat dilihat dari tingkat partisipasi peserta didik untuk bertanya dan menanggapi topik yang dibahas dalam pembelajaran di kelas virtual maupun pertanyaan melalui forum kelas pada google classroom. peserta didik juga mampu menunjukkan kerjasama yang baik antar sesama teman dalam diskusi virtual maupun dalam menyelesaikan jawaban pertanyaan (Collaboration). Jika dibandingkan dengan pembelajaran pertemuan sebelumnya yang dilakukan penulis tanpa menggunakan evalusi berbantuan quizizz suasana kelas virtual cenderung serius dan guru lebih mengambil peran. peserta didik cenderung bekerja sendiri-sendiri untuk berlomba menyelesaikan tugas yang diberikan guru. Fokus guru dalam pembelajaran konvensional adalah bagaimana peserta didik menerima materi dan dapat menyelesikan soal yang disajikan; kurang peduli pada proses berpikir peserta didik. Berbeda kondisinya dengan pembelajaran berbantuan video ini dalam pembelajaran ini pemahaman peserta didik tentang konsep dasar penginderaan jauh melalui video dan diskusi sangat melatih dan menuntut kemampuan peserta didik untuk berpikir kritis dengan cepat. Berikut contoh gambar tayangan video yang diberikan peserta didik dan keaktifan peserta didik dalam diskusi:

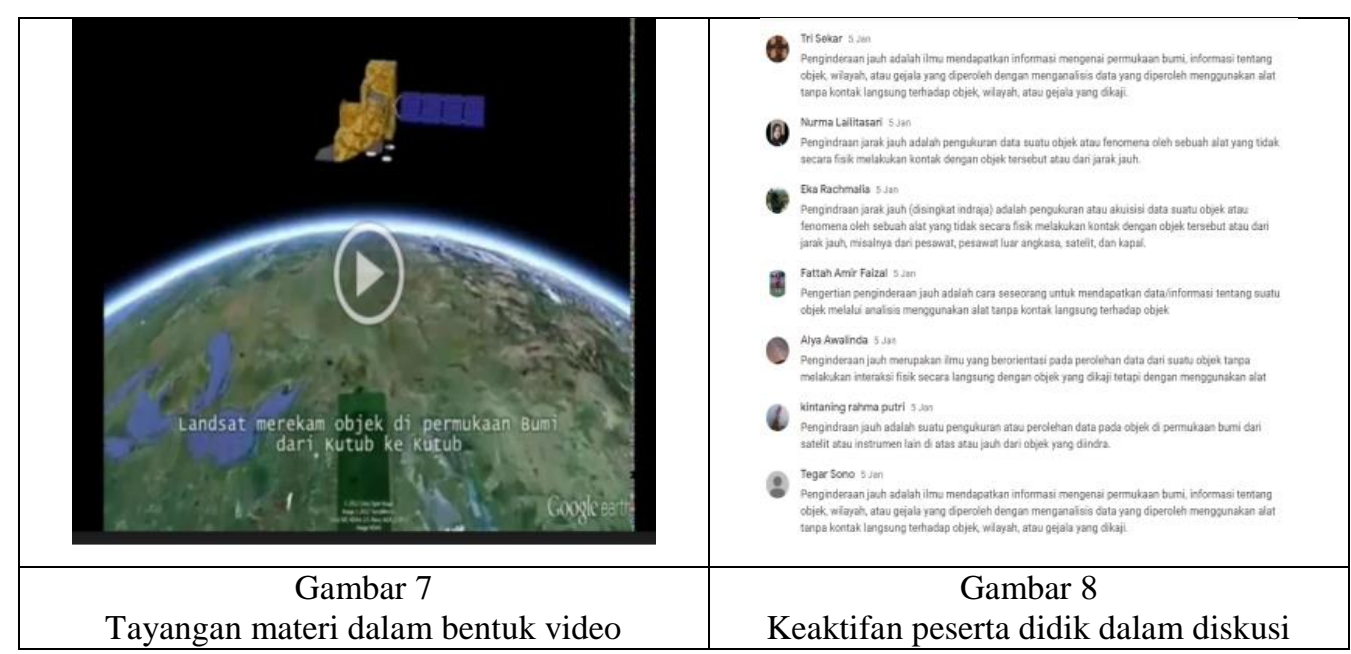

Penerapan pembelajaran berbantuan quizizz dengan pemberian materi berupa video juga meningkatkan kemampuan peserta didik dalam memecahkan masalah (problem solving). Pembelajaran berbantuan video yang diterapkan dengan diskusi akan merangsang peserta didik lebih semangat dalam menyelesaikan permasalahan. Sebelum menerapkan pembelajaran berbantuan video yang diakhiri dengan evalusi berbantuan quizizz, penulis melaksanakan pembelajaran secara konvensional tanpa menggunkan video dan evaluasi dilakukan dengan paper base test yang difoto kemudian dikirimkan melalui googleclassroom. Dengan pembelajaran berbantuan video, peserta didik tidak hanya belajar dari uraian keterangan dalam buku, namun juga peserta didik diberi kesempatan terbuka untuk mencari data dari berbagai sumber. Hasil yang dapat tuliskan dari kegiatan pembelajaran di kelas XII.IPS 5 adalah sebagai berikut:

$\begin{array}{ll}\text { Nilai tertinggi } & : 100 \\ \text { Nilai terendah } & : 53 \\ \text { Rata-rata } & : 87,80 \\ \text { Jumlah peserta didik } & : 33 \\ \text { Hadir pembelajaran dan mengikuti Quiz sampai dengan selesai } & : 29 \\ \text { Hadir pembelajaran tidak mengikuti Quiz sampai dengan selesai } & : 2 \\ \text { Tidak hadir dalam pembelajaran } & : 2 \\ \text { Jumlah peserta didik tuntas } & : 26 \\ \text { Jumlah peserta didik tidak tuntas } & : 3 \\ \text { Persentase peserta didik tuntas } & : 89,6 \% \\ \text { Persentase peserta didik tidak tuntas } & : 11 \%\end{array}$


Tabel 1. Kehadiran Belajar Peserta Didik

\begin{tabular}{lcc}
\hline Kehadiran & Frekuensi & Presentase \\
\hline Hadir & 31 & $94 \%$ \\
Tidak Hadir & 2 & $6 \%$ \\
Jumlah & 33 & $100 \%$ \\
\hline
\end{tabular}

Berdasarkan tabel 1 maka dapat disimpulkan bahwa dari jumlah peserta didik 33 hadir dalam pembelajaran $94 \%$ (31 peserta didik) dan tidak hadir dalam pembelajaran 2 peserta didik (6\%). Hal ini menunjukan bahwa kehadiran peserta didik termasuk kategori amat baik karena lebih dari $86 \%$. Berdasarkan informasi yang diperoleh melalui grup kelas dari dua peserta didik yang tiak hadir disebabkan karena sakit. Berdasarkan deskripsi kehadiran peserta didik di atas tidak semuanya dapat mengikuti pembelajaran sampai dengan evaluasi selesai. Keikutsertaan dalam pembelajaran dan evaluasi berbantuan quizizz yang dapat dilihat pada tebel berikut:

Tabel 2. Keikutsertaan Evalusi dengan Quizizz

\begin{tabular}{lcc}
\hline Keikutsertaan Evaluasi & Frekuensi & Presentase \\
\hline Mengikuti Sampai Dengan Selesai & 29 & $88 \%$ \\
Mengikuti Tidak Sampai Selesai & 2 & $6 \%$ \\
Tidak Mengikuti & 2 & $6 \%$ \\
Jumlah & 33 & $100 \%$ \\
\hline
\end{tabular}

Berdasarkan tabel 2 maka dapat disimpulkan bahwa dari jumlah peserta didik 33 yang hadir dalam pembelajaran dan dapat mengikuti pembelajaran dengan berbantuan quizizz sampai dengan selesai $88 \%$ (29 peserta didik) dan hadir dalam pembelajaran dan mengikuti evaluasi tidak sampai selesai 2 peserta didik (6\%) dan tidak mengikuti pembelajran 2 peserta didik $(6 \%)$. Hal ini menunjukan bahwa keikutsertaan pembelajaran sampai dengan evalusi kategori baik karena lebih dari $71 \%$. Berdasarkan informasi yang diperoleh melalui whatapp grup kelas bahwa dari 2 peserta didik ( $6 \%$ ) yang hadir pembelajaran namun tidak sampai selesai disebabkan karena sinyal yang tidak memungkinkan. Sementara 2 peserta didik $(6 \%)$ tidak mengikuti evalusi karena tidak hadir dalam pembelajran dari awal karena sakit. Berdasarkan keikutsertaan peserta didik dalam pembelajaran sampai dengan evalusi berbantuan quizizz dapat dilihat ketuntuasan belajar peserta didik. Ketuntasan belajara dapat dilihat pada tabel berikut:

Tabel 3. Ketuntasan Belajar Peserta Didik

\begin{tabular}{lcc}
\hline Ketuntasan & Frekuensi & Presentase \\
\hline Tuntas & 26 & $89,7 \%$ \\
Tidak Tuntas & 3 & $10,3 \%$ \\
Jumlah & 29 & $100 \%$ \\
\hline
\end{tabular}

Berdasarkan tabel 1.3 maka dapat disimpulkan bahwa dari jumlah peserta didik 29 yang hadir dalam pembelajaran dan mengikuti evalusi berbantuan quizizz sampai dengan selesai 89,7 \% (26 peserta didik) dan tidak tuntas 2 peserta didik $(10,3 \%)$. Hal ini menunjukan bahwa ketuntasan belajar peserta didik termasuk kategori sangat baik karena lebih dari $86 \%$. Ketuntasan belajar peserta didik juga dapat dilihat dalam bentuk grafik berikut:

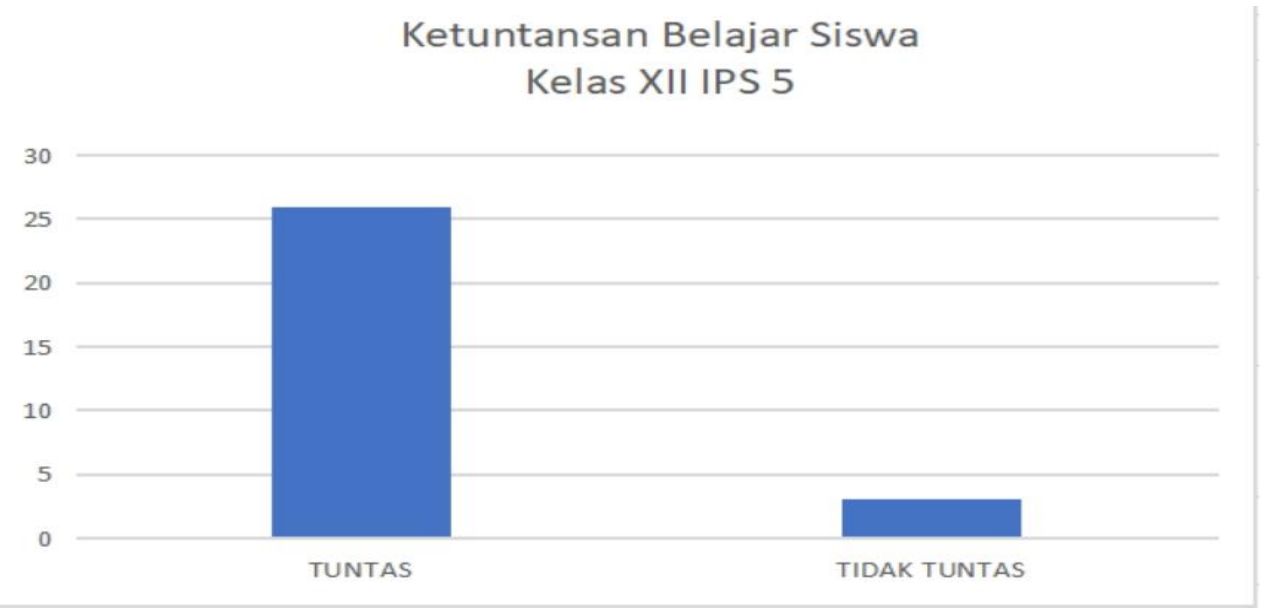

Gambar 9. Grafik Ketuntasan Belajar Siswa Kelas XII IPS 5 
Dari ketuntasan belajar peserta didik setelah dilakukan wawancara diperoleh informasi bahwa ketuntasan belajar peserta didik disebabakan karena sebelum pembelajaran secara vitual guru telah memberikan terlebih dahulu materi yang akan ajarkan di kelas dan adannya motivasi berkompetisi karena evalusi dengan berbantuan quizizz peserta didik dapat melihat progress nilai yang didapat dan langsung mendapatkan komentar oleh guru. peserta didik juga bisa melihat posisi nilai dibanding dengan peserta didik yang lain.

\section{KESIMPULAN}

Pembelajaran geografi berbantuan quizizz sebagai media evalusi layak dijadikan acuan dalam pemilihan strategi pembelajaran di tengah pendemi Covid-19. Disamping itu dengan mengkolaborasikan quizizz dengan penyampaian materi dengan media video, google meet dengan LMS google classroom dapat meningkatkan kemampuan 4C (Communication/mampu berkomunikasi, Collaboration/mampu berkolaborasi atau bekerjasama, Critical Thinking/mampu berfikir kritis, dan Creative dan inovatife/mampu berkreasi dan berinovasi). Pembelajaran geografi berbantuan quizizz sebagai media evaluasi dan mengkolaborasikan quizizz dengan penyampaian materi berupa media video, google meet dengan LMS google classroom merupakan salah satu pembelajaran yang akan menciptakan situasi pembelajaran yang menyenangkan, hal ini disebabkan pembelajaran dengan video berbantuan quizizz dapat meningkatkan jiwa kompetisi peserta didik dalam mendapatkan pengetahuan (transfer knowledge), berpikir kritis dalam memecahkan masalah (critical thinking), dan pemecahan masalah (problem solving). Dengan penyusunan rencana pelaksanaan pembelajaran (RPP) secara sistematis dan cermat, maka pembelajaran geografi berbantuan quizizz sebagai media evaluasi dan mengkolaborasikan quizizz dengan penyampaian materi berupa media video, google meet dengan LMS google classroom maka peserta didik tidak sekadar menerima materi saja, tetapi juga mendapatkan PPK, literasi, dan kecakapan abad 21.

Guru seharusnya tidak hanya mengajar dengan mengacu pada buku teks yang ada saja, tetapi berani melakukan inovasi pembelajaran yang kontekstual sesuai dengan latar belakang peserta didik yang hidup pada era digitalisasi, dan situasi kondisi sekolahnya. Hal ini akan membuat pembelajaran lebih bermakna, dan melatih guru untuk mencoba menganalisis materi dan memotivasi guru untuk membuat video pembelajaran mandiri. Di akhir kegiatan belajar mengajar sebelum evalusi beberapa kelompok perlu melakukan presentasi virtual tentang hasil diskusi kelompok yang mengacu pada permasalahan dalam LKPD, dan menyampaikan jawabannya sebagai hasil diskusi kelompok, hal ini termasuk ke dalam kemampuan berkomunikasi (Communication). Peserta didik diharapkan untuk menerapkan kemampuan berpikir tingkat tinggi dalam belajar, tidak terbatas pada hafalan teori. Kemampuan belajar dengan cara ini akan membantu peserta didik menguasai materi secara lebih mendalam. Sekolah, terutama kepala sekolah dapat mendorong semua guru untuk ikut melaksanakan pembelajaran berbasis teknologi, yang menjadi sangat penting di tengah pandemi Covid-19. Dukungan positif sekolah, seperti menyediakan sarana dan prasarana yang memadai dan memberikan peluang guru dan siswa untuk belajar agar tidak tertinggal dengan perubahan.

\section{DAFTAR PUSTAKA}

[1] W. A. F. Dewi, "Dampak COVID-19 terhadap Implementasi Pembelajaran Daring di Sekolah Dasar," Edukatif J. Ilmu Pendidik., vol. 2, no. 1, pp. 55-61, 2020, doi: 10.31004/edukatif.v2i1.89.

[2] M. L. Famukhit, "Google Classroom Sebagai Media Pembelajaran Daring Online Pada Program Studi Pendidikan Informatika Stkip Pgri Pacitan,” J. Penelit. Pendidik., vol. 12, no. 1, 2020, [Online]. Available: http://www.ejournal.stkippacitan.ac.id/index.php/jpp/article/view/314.

[3] Y. I. Aini, "Pemanfaatan Media Pembelajaran Quizizz Untuk Pembelajaran Jenjang Pendidikan Dasar Dan Menengah Di Bengkulu," J. Kependidikan, vol. 2, no. 25, pp. 1-6, 2019.

[4] C. A. Citra and B. Rosy, "Keefektifan Penggunaan Media Pembelajaran Berbasis Game Edukasi Quizizz Terhadap Hasil Belajar Teknologi Perkantoran Siswa Kelas X SMK Ketintang Surabaya,” J. Pendidik. Adm. Perkantoran, vol. 8, pp. 261-272, 2020, [Online]. Available:

https://journal.unesa.ac.id/index.php/jpap/article/view/8242/4081.

[5] I. A. D. I. Nugroho, "Pembuatan soal Menggunakan Aplikasi Quizizz," UST Jogja, 2019.

[6] MPOC, “No 主観的健康感を中心とした在宅高齢者における 健康関連指標に関する共分散構造分析 Title," Malaysian Palm Oil Counc., vol. 21, no. 1, pp. 1-9, 2020, [Online]. Available: http://mpoc.org.my/malaysian-palm-oil-industry/.

[7] Firman and S. R. Rahman, "Pembelajaran Online di Tengah Pandemi Covid-19 Firman1, Sari Rahayu Rahman1,” Indones. J. Educ. Sci., vol. 2, no. 2, pp. 81-89, 2020.

[8] I. Farida, R. R. Sunarya, R. Aisyah, and I. Helsy, "Pembelajaran Kimia Sistem Daring di Masa Pandemi Covid-19 Bagi Generasi Z,” KTI UIN Sunan Gunung Djati, pp. 1-11, 2020, [Online]. Available: http://digilib.uinsgd.ac.id/30638/.

[9] N. N. Kharisma, M. V. Roesminingsih, and S. Suhanadji, "Gambaran kebutuhan pembelajaran daring pkbm budi utama surabaya pada masa pandemi covid-19,” J. Pendidik. Nonform., vol. 15, no. 1, pp. 38-44, 2020. 